\begin{tabular}{|c|l|}
\hline Title & Origin of activated combustion in steady-state premixed burner flame with superposition of dielectric barrier discharge \\
\hline Author(s) & Zaima, Kazunori; A kashi, Haruaki; Sasaki, Koichi \\
\hline Citation & $\begin{array}{l}\text { Japanese Journal of A pplied Physics (JJA P), 55(1), 016201 } \\
\text { https://doi.org/10.7567/JJA.55.016201 }\end{array}$ \\
\hline Issue Date & 2016-01 \\
\hline Doc URL & http://hdl.handle.net/2115/63681 \\
\hline Rights & ○ 2016 The Japan Society of A pplied Physics \\
\hline Type & article (author version) \\
\hline File Information & RP150328.pdf \\
\hline
\end{tabular}

Instructions for use 


\title{
Origin of activated combustion in steady-state premixed burner flame with superposition of dielectric barrier discharge
}

\author{
Kazunori Zaima ${ }^{1}$, Haruaki Akashi ${ }^{2}$, and Koichi Sasaki ${ }^{1 *}$ \\ ${ }^{1}$ Division of Quantum Science and Engineering, Hokkaido University, Sapporo 060-8628, Japan \\ ${ }^{2}$ Department of Applied Physics, National Defense Academy, Yokosuka, Kanagawa 239-8686, Japan
}

\begin{abstract}
The objective of this work is to understand the mechanism of plasma-assisted combustion in a steadystate premixed burner flame. We examined the spatiotemporal variation of the density of atomic oxygen in a premixed burner flame with the superposition of dielectric barrier discharge (DBD). We also measured the spatiotemporal variations of the optical emission intensities of $\mathrm{Ar}$ and $\mathrm{OH}$. The experimental results reveal that atomic oxygen produced in the preheating zone by electron impact plays a key role in the activation of combustion reactions. This understanding is consistent with that described in our previous paper indicating that the production of "cold $\mathrm{OH}\left(\mathrm{A}^{2} \Sigma^{+}\right)$" via $\mathrm{CHO}+\mathrm{O} \rightarrow \mathrm{OH}\left(\mathrm{A}^{2} \Sigma^{+}\right)+\mathrm{CO}$ has the sensitive response to the pulsed current of DBD [K. Zaima and K. Sasaki, Jpn. J. Appl. Phys. 53, 110309 (2014)].
\end{abstract}

\section{Introduction}

Plasma-assisted combustion ${ }^{1)}$ has been a growing research field in recent years as a technology to achieve the reduced consumption of fossil fuels and to avoid global warming. This technology has potential in realizing combustion of lean fuels ${ }^{2-6)}$ and water-containing biomass fuels. In addition, combustion in speedy flow becomes possible by the superposition of a plasma. ${ }^{7-12)}$ The increase in burning velocity ${ }^{13-21)}$ and the improvement of ignition characteristics $^{22-28)}$ have been observed in plasma-assisted combustion.

It is believed that high-energy electrons produced by a nonequilibrium plasma play essential roles in plasma-assisted combustion, and electron impact processes such as dissociation, excitation, and ionization are the origins of activated combustion reactions. For example, we have reported a unique relationship between the increase in burning velocity and the number of high-energy electrons in a plasma-assisted steady-state premixed burner flame. ${ }^{21)}$ However, the detailed roles of high-energy electrons have not been understood yet. The objective of this work is to understand the key species, which are produced with the help of high-energy electrons, in plasma-assisted combustion of a steady-state premixed burner flame.

"E-mail: sasaki@qe.eng.hokudai.ac.jp 
The hydroxyl radical $(\mathrm{OH})$ is understood widely as an important species in combustion chemistry. In a previous work, we examined the temporal variation of the $\mathrm{OH}$ radical density in a premixed burner flame with the superposition of dielectric barrier discharge (DBD). ${ }^{29)}$ As a result, we observed a slight increase in $\mathrm{OH}$ radical density by the superposition of DBD. However, it was also observed that the $\mathrm{OH}$ radical density had a negligible temporal variation within a cycle of DBD, even though DBD provided high-energy electrons intermittently. This means that the increase in $\mathrm{OH}$ density does not have a direct response to high-energy electrons. In other words, the increase in $\mathrm{OH}$ density is not the origin but is a result of activated combustion chemistry in the plasma-assisted flame. On the other hand, in the same work, ${ }^{29)}$ we also observed pulsed increases in the optical emission intensity of $\mathrm{OH}$ [or the density of $\left.\mathrm{OH}\left(\mathrm{A}^{2} \Sigma^{+}\right)\right]$at the timings of the pulsed current of DBD. The increase in $\mathrm{OH}\left(\mathrm{A}^{2} \Sigma^{+}\right)$density was not dominated by electron impact excitation, and a considerable part of the increase in $\mathrm{OH}\left(\mathrm{A}^{2} \Sigma^{+}\right)$density was due to chemical reactions. In addition, it was observed that $\mathrm{OH}\left(\mathrm{A}^{2} \Sigma^{+}\right)$ produced at the timings of the pulsed current had a low rotational temperature. On the basis of the literature, ${ }^{30,31)}$ it has been speculated that the chemical reaction that produces "cold $\mathrm{OH}\left(A^{2} \Sigma^{+}\right)$" is $\mathrm{CHO}+\mathrm{O} \rightarrow \mathrm{OH}\left(\mathrm{A}^{2} \Sigma^{+}\right)+\mathrm{CO}$. Note that this reaction needs atomic oxygen on the left-hand side.

As mentioned above, our previous work suggests the importance of atomic oxygen, which can be produced by electron impact dissociation of $\mathrm{O}_{2}$, in plasma-assisted combustion of the steady-state premixed burner flame. In this work, we examined the density of atomic oxygen to investigate its importance in the activated combustion chemistry in the plasma-assisted flame. The experimental results suggest the importance of atomic oxygen produced in the preheating zone as the origin of activated combustion chemistry in the plasma-assisted flame.

\section{Experimental methods}

The experimental apparatus is schematically shown in Fig. 1. We employed a premixed burner (Takamitsu 20A $\mathrm{A}_{1}$ ) with a $\mathrm{CH}_{4} / \mathrm{O}_{2} / \mathrm{Ar}$ mixture. The outer diameter of the burner was $12 \mathrm{~mm}$. It had a main nozzle of $2 \mathrm{~mm}$ diameter at the center, and the main nozzle was surrounded by eight subnozzles with a diameter of $1.7 \mathrm{~mm} .{ }^{20)}$ The flow rates of $\mathrm{CH}_{4}, \mathrm{O}_{2}$, and Ar were adjusted at $0.38,1.0$, and $5.6 \mathrm{slm}$, respectively, using mass flow controllers. The mass flow controllers were connected to the burner via a gas mixing system. The burner was attached to a dielectric base plate and electrically grounded. The length of the flame was approximately $85 \mathrm{~mm}$. The upper part of the flame was covered with a quartz tube with inner and outer diameters of 7 and $10 \mathrm{~mm}$, respectively. The distance between the bottom side of the quartz 
tube and the top of the burner nozzle was $13 \mathrm{~mm}$. An aluminum electrode, which had an inner diameter of $10.1 \mathrm{~mm}$ and a height of $10 \mathrm{~mm}$, was attached to the outside of the quartz tube and connected to a high-voltage power supply with a rectangular waveform. The distance between the bottom side of the aluminum electrode and the top of the burner nozzle was $25 \mathrm{~mm}$. This electrical configuration resulted in an asymmetric DBD inside the quartz tube between the aluminum electrode and the burner nozzle. The discharge power, which was averaged over the cycle of discharge voltage, was $5 \mathrm{~W}$, while the chemical power yielded via combustion reactions was $250 \mathrm{~W}$. The averaged discharge power corresponded to the instantaneous power of $\sim 25 \mathrm{~kW}$ at the timings of current pulses, by considering the waveform of the discharge current described below.

Two-photon laser-induced fluorescence (TALIF) spectroscopy was adopted for measuring the density of atomic oxygen. A laser beam yielded from an optical parametric oscillator (OPO) was focused using a lens and injected into the flame from the radial direction. Since the focal length of the lens was $250 \mathrm{~mm}$, the intensity distribution of the incident laser beam was roughly uniform along its path around the focus in the region of $-5 \leq r \leq 5 \mathrm{~mm}$. The axial distance between the burner nozzle and the laser beam was $3 \mathrm{~mm}$. The laser wavelength was $225.58 \mathrm{~nm}$, which excited atomic oxygen at the ground state $\left(2 \mathrm{p}^{4} \mathrm{P}\right)$ to the $2 \mathrm{p}^{3} 3 \mathrm{p}^{3} \mathrm{P}$ state. The transition from the laser-excited $2 \mathrm{p}^{3} 3 \mathrm{p}^{3} \mathrm{P}$ state to the $2 \mathrm{p}^{3} 3 \mathrm{~s}^{3} \mathrm{~S}$ state emitted the fluorescence at a wavelength of $844.7 \mathrm{~nm}$. The fluorescence was detected using a chargecoupled device camera with a gated image intensifier (ICCD camera) from the normal angle to the incident laser beam. An interference filter with the transmission at $844 \pm 1 \mathrm{~nm}$ was placed in front of the ICCD camera to separate the TALIF emission from the stray light and the self-emission of DBD. The image of the TALIF emission was accumulated for 2500 laser shots to compensate for the poor shot-to-shot reproducibility. We thus obtained the radial density distribution of atomic oxygen along the path of the OPO laser beam. The oscillation of the OPO laser was synchronized with the waveform of the discharge voltage. By changing the delay time between the stepwise increase in discharge voltage and the oscillation of the OPO laser, we obtained the temporal variation of the density of atomic oxygen within a cycle of DBD.

We employed spatially resolved optical emission spectroscopy for measuring the optical emission spectra of Ar and $\mathrm{OH}$. The horizontal image of the optical emission at a distance of $3 \mathrm{~mm}$ from the burner nozzle was projected into the entrance side of a linearly aligned optical fiber array using a lens. The exit side of the optical fiber array was placed at a close distance to the entrance slit of a spectrograph with a focal length of $500 \mathrm{~mm}$. The spectrograph was 
equipped with a diffractive grating of 2400 grooves/mm and an ICCD camera. The $x$-axis of the image recorded using the ICCD camera corresponded to the wavelength, while the $y$-axis corresponded to the horizontal position of the flame. We thus obtained the optical emission spectra at various horizontal positions. The radially resolved optical emission intensity was obtained by adopting the Avel inversion. The optical fiber array was composed of 32 elements, and the spatial resolution of the measurement was approximately $0.08 \mathrm{~mm}$. The gate opening of the ICCD camera was synchronized with the waveform of the discharge voltage, and we recorded the temporal variation of the optical emission intensity within a cycle of DBD.

\section{Results}

The waveforms of the discharge voltage and the discharge current are shown in Fig. 2. The waveform of the discharge current was obtained by averaging 512 cycles on a digital oscilloscope. A single current pulse was observed in the rising phase of the voltage, while we observed three current pulses in the falling phase. The current pulse in a single cycle had a duration of $\sim 5 \mu$ s. However, since the jitter in the discharge current pulse was unavoidable in DBD, the average current waveforms had longer durations, as shown in Fig. 2.

Figure 3(a) shows the radial distributions of the $\mathrm{O}$ densities in the absence and presence of DBD. The measurement in the presence of DBD was carried out at the timing of the pulsed current ( $t=0.6 \mathrm{~ms}$ in Fig. 2). Figure 3(b) shows the radial distribution of the gas temperature, which was evaluated by laser Rayleigh scattering as described in a previous paper. ${ }^{21)}$ The central part of the premixed burner flame was occupied by unburned gas. ${ }^{32)}$ The unburned gas region had a negligible $\mathrm{O}$ density and a low gas temperature close to room temperature. The gas temperature increased with the radial distance from the center and reached $\sim 1600 \mathrm{~K}$ at $r \geq 1.5 \mathrm{~mm}$. The radial increase in $\mathrm{O}$ density was steeper than that in gas temperature. The maximum $\mathrm{O}$ density was observed at $r \simeq 1.6 \mathrm{~mm}$. The region with the high gas temperature and high $\mathrm{O}$ density is understood to be the reaction zone, and the transition region from the unburned gas to the reaction zone is called the preheating zone. ${ }^{32)}$ The preheating zone had a medium gas temperature, as shown in Fig. 3(b). Although the boundaries among the regions are not definite, in this paper, the regions of $r \lesssim 0.9,0.9 \lesssim r \lesssim 1.4$, and $r \gtrsim 1.4$ $\mathrm{mm}$ are categorized into the unburned gas, preheating zone, and reaction zone, respectively, as indicated in Fig. 3 by the vertical dotted lines. The $\mathrm{O}$ density decreased gradually with the radius in the outside region of the reaction zone. The $\mathrm{O}$ density in the outside region in the presence of DBD was lower than that in the absence of DBD. On the other hand, the gas 
temperature was unchanged by DBD as reported in the previous paper. ${ }^{21)}$

The influence of DBD on the $\mathrm{O}$ densities in the preheating and reaction zones is not seen clearly in Fig. 3(a). To show the difference, we plot the ratio of the $\mathrm{O}$ densities in the absence and presence of DBD in Fig. 4(a). The measurement time in the presence of DBD was $t=0.6$ $\mathrm{ms}$ in Fig. 2. Plotting the ratio in the unburned gas region was impossible since both the $\mathrm{O}$ densities in the presence and absence of DBD were negligible. Figure 4(b) shows the radial distribution of the gas temperature in the same radial region. As shown in Fig. 4(a), the ratio of the $\mathrm{O}$ densities in the reaction zone was close to unity. On the other hand, we observed the spatial perturbation of the ratio of the $\mathrm{O}$ densities in the preheating zone.

Figure 5 shows the temporal variations of the ratio of the $\mathrm{O}$ densities in the absence and presence of DBD at three radial positions. The jitter of the current pulses distorted the temporal resolution of this measurement, since each plot in Fig. 5 was obtained by accumulating TALIF signals for 2500 laser shots. However, we can compare the temporal variation shown in Fig. 5 with that in Fig. 2, since Fig. 2 was also obtained by the accumulated measurement. We observed the oscillation of the ratio of the $\mathrm{O}$ densities in the preheating zone $(r=1.0$ $\mathrm{mm}$ ), as shown in Fig. 5(a). The oscillation was mainly observed at the timings of the pulsed current. The $\mathrm{O}$ density in the presence of DBD was temporally higher than that in the absence of DBD. The higher O density was followed by a steep decrease, and we temporally observed an $\mathrm{O}$ density that was lower than that in the absence of DBD. At the inner edge of the reaction zone ( $r=1.5 \mathrm{~mm}$ ), as shown in Fig. 5(b), the $\mathrm{O}$ density in the presence of DBD was slightly higher than that in the absence of DBD in the period without the discharge current, but we observed the temporal decrease in $\mathrm{O}$ density at the timings of the pulsed current. At the outer edge of the reaction zone $(r=2.0 \mathrm{~mm})$, as shown in Fig. 5(c), the $\mathrm{O}$ densities in the presence and absence of DBD were almost the same in the period without the discharge current, but the temporal decrease in $\mathrm{O}$ density was observed at the timings of the pulsed current.

Figures 6(a) and 6(b) show the radial distributions of the optical emission intensities of $\mathrm{OH}$ and Ar, respectively. The optical emission intensity of $\mathrm{OH}$ plotted in Fig. 6(a) is wavelength-integrated over the band spectrum of the $\mathrm{A}^{2} \Sigma^{+}\left(v^{\prime}=0\right)-\mathrm{X}^{2} \Pi\left(v^{\prime \prime}=0\right)$ transition $(305 \leq \lambda \leq 313 \mathrm{~nm})$. The observed transition of Ar was $4 \mathrm{~s}[3 / 2]_{2}^{\mathrm{o}}-4 \mathrm{p}[5 / 2]_{3}(\lambda=811$ $\mathrm{nm})$. The negative optical emission intensities in the central region were due to the error in the Avel inversion. The observation times in Fig. $6(t=0.1$ and $0.6 \mathrm{~ms})$ correspond to the horizontal axis of Fig. 2. The distribution of the optical emission intensity of $\mathrm{OH}$ in the absence of DBD is plotted in Fig. 6(a) for comparison. The optical emission of Ar was observed only at the timings of the pulsed current. As shown in the figure, the radial distributions of 
the optical emission intensities of $\mathrm{OH}$ and Ar were similar in the radial region of $r \geq 1.4 \mathrm{~mm}$. On the other hand, at $0.9 \lesssim r \lesssim 1.4 \mathrm{~mm}$, the distribution of the optical emission intensity of $\mathrm{OH}$ was more gradual than that of Ar, and we observed the optical emission intensity of $\mathrm{OH}$ even in the region with the negligible optical emission intensity of $\operatorname{Ar}(r \lesssim 1.2 \mathrm{~mm})$.

The experimental results shown in Fig. 6 are replotted in Fig. 7 to show the relationship between the optical emission intensities of $\mathrm{Ar}$ and $\mathrm{OH}$. The vertical axis of Fig. 7 shows the difference between the optical emission intensities of $\mathrm{OH}$ in the presence and absence of $\mathrm{DBD}\left[I_{\mathrm{OH}}(\mathrm{ON})-I_{\mathrm{OH}}(\mathrm{OFF})\right]$. The data in the region with negligible (negative) $I_{\mathrm{Ar}}$ are plotted at $I_{\mathrm{Ar}}=0$ in Fig. 7. The radial region of $1.0 \leq r \leq 2.0 \mathrm{~mm}$ is divided into five regions, and different plot symbols are employed in Fig. 7. As shown in Fig. 7, roughly proportional relationships were found between $I_{\mathrm{OH}}(\mathrm{ON})-I_{\mathrm{OH}}(\mathrm{OFF})$ and $I_{\mathrm{Ar}}$ at $1.4 \leq r \leq 2.0 \mathrm{~mm}$ (the reaction zone). On the other hand, in the inner radial region of $1.0 \leq r \leq 1.4 \mathrm{~mm}$ (the preheating zone), $I_{\mathrm{OH}}(\mathrm{ON})-I_{\mathrm{OH}}(\mathrm{OFF})$ was stronger than that expected from the proportional relationship.

\section{Discussion}

The experimental result shown in Fig. 3 indicates that the amount of atomic oxygen produced by DBD is negligible in the reaction zone. In other words, the amount of atomic oxygen produced by combustion reactions is much larger than that produced by the effect of high-energy electrons of DBD. This is reasonable by considering the absolute $\mathrm{O}$ density in the flame, which is estimated to be on the order of $10^{16} \mathrm{~cm}^{-3}$ by numerical simulation using Chemkin (the result of the numerical simulation will be shown in Fig. 8). On the other hand, as reported in a previous paper, ${ }^{21)}$ it is certain that a higher burning velocity is obtained by superposing DBD onto the premixed burner flame. The higher burning velocity is understood from Fig. 3, which shows the shrinkage of the radial distribution of the $\mathrm{O}$ density in the outside region by the superposition of DBD. According to the structure of the premixed burner flame, the shrinkage of the radius of the reaction zone is linked to the increase in the burning velocity. ${ }^{32)}$

Although the $\mathrm{O}$ densities in the presence and absence of DBD were almost the same in the reaction zone, we observed the effect of $\mathrm{DBD}$ on the $\mathrm{O}$ density in the preheating zone, as shown in Figs. 4 and 5. This means that the amount of atomic oxygen produced by the effect of high-energy electrons is significant in comparison with that produced by combustion reactions in the preheating zone. In particular, the oscillation of the ratio of the $\mathrm{O}$ densities shown in Fig. 5(a) is important to understand the origin of improved combustion reactions in the plasma-assisted flame, since marked oscillations were observed at the timings of the 
pulsed current or the intermittent production of high-energy electrons. We observed a higher $\mathrm{O}$ density at the timing of the pulsed current for a short period, but it was followed by a rapid decrease, resulting in an $\mathrm{O}$ density that was lower than that in the absence of DBD. The rapid decrease in $\mathrm{O}$ density suggests that atomic oxygen produced by the effect of highenergy electrons is so reactive that it is consumed by combustion reactions immediately after its formation. The spatial perturbation in the ratio of the $\mathrm{O}$ densities, which is shown in Fig. 4, could also be explained by the production and consumption of atomic oxygen.

To examine the effect of the additional atomic oxygen in the preheating zone on combustion reactions, we carried out numerical simulation on the temporal evolutions of radical densities using Chemkin. ${ }^{33)}$ The reaction data set was GRI-Mech3.0. The gas composition assumed in the simulation was $\mathrm{CH}_{2} / \mathrm{O}_{2} / \mathrm{Ar}=0.05 / 0.14 / 0.81$. Figure 8 (a) shows the temporal evolutions of the densities of $\mathrm{H}, \mathrm{O}, \mathrm{OH}, \mathrm{CH}$, and $\mathrm{CHO}$ in the simulation of a conventional combustion. Figure 8(c) shows the same data as that in Fig. 8(a), but the horizontal axis is plotted on a linear scale. The combustion reactions are triggered at $t=0 \mathrm{~s}$ by assuming an initial gas temperature of $1000 \mathrm{~K}$, which is the temperature in the preheating zone. As shown in Figs. 8(a) and 8(c), gradual increases in radical densities were observed up to $t \simeq 1.39 \mathrm{~s}$. The gradual increases were followed by abrupt increases in radical densities, resulting in the ignition of the combustion. On the other hand, in Figs. 8(b) and 8(d), the initial O density was set at $2 \times 10^{14} \mathrm{~cm}^{-3}$ artificially to simulate the effect of additional atomic oxygen produced by DBD. This artificial $\mathrm{O}$ density corresponds to a degree of dissociation of $1 \times 10^{-4}$ for fed molecular oxygen and is a possible value of the $\mathrm{O}$ density produced by the electron impact dissociation of $\mathrm{O}_{2}$ in DBD. As shown in Fig. 8(b), we observed the increases in the densities of $\mathrm{H}, \mathrm{OH}, \mathrm{CHO}$, and $\mathrm{CH}$ in the period with the constant $\mathrm{O}$ density ( $t \leq 5 \mu \mathrm{s})$. After that, the radical densities decreased with a time constant of approximately $10 \mu \mathrm{s}$. These quite rapid decreases were followed by gradual decreases with a time constant of approximately 10 ms. However, the radical densities after the decreases were higher than those in the conventional combustion at the same delay time. Finally, the simulation with the initial $\mathrm{O}$ density of $2 \times 10^{14} \mathrm{~cm}^{-3}$ resulted in a shorter ignition delay time of $\simeq 1.23 \mathrm{~s}$. The radical densities after the ignition were almost independent of the initial $\mathrm{O}$ density.

Although the present experiment was carried out in a steady-state premixed burner flame, the temporal evolutions of the radical densities obtained by the simulation are understood as an analogy of the experimental results by converting the time in the simulation into the radial position in the experiment. This is because the radial structure of the steady-state premixed burner flame from the preheating to reaction zones includes similar chemistry to the temporal 
evolution from the low-temperature oxidation to the ignition. The period after the ignition corresponds to the reaction zone, and the period of low-temperature oxidation (before the ignition) corresponds to the preheating zone. From this point of view, the decrease in $\mathrm{O}$ density shown in Fig. 8(b) corresponds to the oscillation of the $\mathrm{O}$ density shown in Fig. 5(a). The simulation result showing the same $\mathrm{O}$ densities after the ignition corresponds to the same $\mathrm{O}$ densities in the reaction zone in the experiment. The shortened ignition delay time in the simulation corresponds to the increased burning velocity. Therefore, the present experimental results, with the help of numerical simulation, suggest the importance of the additional atomic oxygen in the preheating zone in plasma-assisted combustion of the steady-state premixed burner flame.

The importance of atomic oxygen in the preheating zone is consistent with that described in our previous paper indicating the chemical production of $\mathrm{OH}\left(\mathrm{A}^{2} \Sigma^{+}\right)$at the timings of the pulsed current. ${ }^{29)}$ Let us assume that the optical emission intensity of $\mathrm{OH}$ or the density of $\mathrm{OH}\left(A^{2} \Sigma^{+}\right)$in the DBD-assisted flame has two origins and is given by

$$
I_{\mathrm{OH}}=I_{\mathrm{OH}}^{0}+I_{\mathrm{OH}}^{\mathrm{e}}
$$

where $I_{\mathrm{OH}}^{\mathrm{e}}$ denotes the component originating from the effect of high-energy electrons and $I_{\mathrm{OH}}^{0}$ is the component observed in the flame without the superposition of DBD. If we assume that $I_{\mathrm{OH}}$ and $I_{\mathrm{OH}}^{0}$ correspond to $I_{\mathrm{OH}}(\mathrm{ON})$ and $I_{\mathrm{OH}}(\mathrm{OFF})$, respectively, the vertical axis of Fig. 7 gives us the estimation of $I_{\mathrm{OH}}^{\mathrm{e}}$. According to the concept of actinometry, ${ }^{34)}$ if both $I_{\mathrm{Ar}}$ and $I_{\mathrm{OH}}^{\mathrm{e}}$ are dominated by electron impact excitation, a proportional relationship should be found between them. As shown in Fig. 7, the proportional relationship is observed at $1.4 \leq r \leq 2.0$ $\mathrm{mm}$. This region corresponds to the reaction zone. On the other hand, at $1.0 \leq r \leq 1.4 \mathrm{~mm}$, $I_{\mathrm{OH}}^{\mathrm{e}}$ is greater than that expected by the proportional relationship. This region corresponds to the preheating zone. The deviation from the proportional relationship means that the optical emission of $\mathrm{OH}$ in this radial region is not dominated by electron impact excitation. In other words, the optical emission intensity of $\mathrm{OH}$ at $1.0 \leq r \leq 1.4 \mathrm{~mm}$ indicates the production of $\mathrm{OH}\left(A^{2} \Sigma^{+}\right)$by chemical reactions. As reported in the previous paper, ${ }^{29)}$ the reaction that produces $\mathrm{OH}\left(\mathrm{A}^{2} \Sigma^{+}\right)$is estimated to be $\mathrm{CHO}+\mathrm{O} \rightarrow \mathrm{OH}\left(\mathrm{A}^{2} \Sigma^{+}\right)+\mathrm{CO}$. Since atomic oxygen on the left-hand side of this reaction is provided by the effect of high-energy electrons, the optical emission intensity of $\mathrm{OH}$ or the density of $\mathrm{OH}\left(\mathrm{A}^{2} \Sigma^{+}\right)$has a sensitive response to the pulsed current, as described in the previous paper. ${ }^{29)}$ 


\section{Conclusions}

In this work, we examined the spatiotemporal variation of the density of atomic oxygen in a premixed burner flame with the superposition of DBD. The experimental results suggest the importance of atomic oxygen produced by DBD in the preheating zone. This understanding is consistent with that described in our previous paper. ${ }^{29)}$ Although the amount of atomic oxygen produced by DBD is much smaller than that produced by combustion chemistry in the reaction zone, it may work as a key in plasma-assisted combustion of the steady-state premixed burner flame.

\section{Acknowledgment}

This work was supported by JSPS KAKENHI Grant Number 25286078. 


\section{References}

1) S. M. Starikovskaia, J. Phys. D 39, R265 (2006).

2) Y. Ikeda, A. Nishiyama, Y. Wachi, and M. Kaneko, SAE Int. 2009-01-1050 (2009).

3) Y. Ikeda, A. Nishiyama, H. Katano, M. Kaneko, and J. Han, SAE Int. 2009-01-1049 (2009).

4) G. Pilla, D. Galley, D. A. Kacoste, F. Lacas, D. Veynante, and C. O. Laux, IEEE Trans. Plasma Sci. 34, 2471 (2006).

5) X. Rao, S. Hammack, T. Lee, C. Carter, and I. B. Matveev, IEEE Trans. Plasma Sci. 38, 3265 (2010)

6) Q. L. L. Pham, D. A. Lacoste, and C. O. Laux, IEEE Trans. Plasma Sci. 39, 2264 (2011).

7) S. B. Leonov, D. A. Yarantsev, A. P. Napartovich, and I. V. Kochetov, IEEE Trans. Plasma Sci. 34, 2514 (2006).

8) I. Esakov, L. P. Grachev, K. V. Khodataev, V. A. Vinogradov, and D. M. van Wie, IEEE Trans. Plasma Sci. 34, 2497 (2006).

9) S. V. Leonov and D. A. Yarantsev, Plasma Sources Sci. Technol. 16, 132 (2007).

10) A. Vincent-Randonnier, S. Larigaldie, P. Magre and V. Sabel'nikov, Plasma Sources Sci. Technol. 16, 149 (2007).

11) T. Ombrello, X. Qin, and Y. Ju, AIAA J. 44, 142 (2006).

12) T. Ombrello, Y. Ju, and A. Fridman, AIAA J. 46, 2424 (2008).

13) S. Stange, Y. Kim, V. Ferreri, L. A. Rosocha, and D. M. Coates, IEEE Trans. Plasma Sci. 33, 316 (2005).

14) Y. Kim, V. W. Ferreri, L. A. Rosocha, G. K. Anderson, S. Abbate, and K.-T. Kim, IEEE Trans. Plasma Sci. 34, 2532 (2006).

15) K. Shinohara, N. Takada, and K. Sasaki, J. Phys. D 42, 182008 (2009).

16) E. S. Stockman, S. H. Zaidi, R. B. Miles, C. D. Carter, and M. D. Ryan, Combust. Flame 156, 1453 (2009).

17) J. Tang, W. Zhao, and Y. Duan, IEEE Trans. Plasma Sci. 38, 3272 (2010).

18) T. Ombrello, S. H. Won, Y. Ju, and S. Williams, Combust. Flame 157, 1906 (2010).

19) T. Ombrello, S. H. Won, Y. Ju, and S. Williams, Combust. Flame 157, 1916 (2010).

20) K. Sasaki and K. Shinohara, J. Phys. D 45, 455202 (2012).

21) K. Zaima and K. Sasaki, Jpn. J. Appl. Phys. 53, 066202 (2014).

22) S. Y. Pancheshnyi, D. A. Lacoste, A. Bourdon, and C. O. Laux, IEEE Trans. Plasma 
Sci. 34, 2478 (2006).

23) G. Lou, A. Bao, M. Nishihara, S. Keshav, Y. G. Utkin, J. W. Rich, W. R. Lempert, and I. V. Adamovich, Proc. Combust. Inst. 31, 3327 (2007).

24) A. Bao, Y. G. Utkin, S. Keshav, G. Lou, and I. V. Adamovich, IEEE Trans. Plasma Sci. 35, 1628 (2007).

25) N. L. Aleksandrov, S. V. Kindysheva, I. N. Kosarev, S. M. Starikovskaia, and A. Y. Starikovskii, Proc. Combust. Inst. 32, 205 (2009).

26) L. Wu, J. Lane, N. P. Cernansky, D. L. Miller, A. Fridman, and A. Y. Starikovskiy, Proc. Combust. Inst. 33, 3219 (2011).

27) W. Sun, M. Uddi, T. Ombrello, S. H. Won, C. Carter, and Y. Ju, Proc. Combust. Inst. 33, 3211 (2011).

28) W. Sun, S. H. Won, T. Ombrello, C. Carter, and Y. Ju, Proc. Combust. Inst. 34, 847 (2013).

29) K. Zaima and K. Sasaki, Jpn. J. Appl. Phys. 53, 110309 (2014).

30) K. H. Becker and D. Kley, Chem. Phys. Lett. 4, 62 (1969).

31) K. H. Becker, D. Kley, and R. J. Norstrom, in Molecular Luminescence, ed. E. C. Lim (Benjamin, New York, 1969) p. 509.

32) A. G. Gaydon and H. G. Wolfhard, Flames: Their Structure, Radiation and Temperature, (Chapman and Hall, London, 1979) 4th ed.

33) http://www.reactiondesign.com/products/chemkin/

34) J. W. Coburn and M. Chen, J. Appl. Phys. 51, 3134 (1980). 


\section{Figure captions}

Figure 1 Experimental apparatus. (a) Two-photon absorption laser-induced fluorescence for measuring the density of atomic oxygen and (b) spatially resolved optical emission spectroscopy for measuring the optical emission intensities of $\mathrm{OH}$ and Ar.

Fugure 2 Waveforms of the discharge voltage and the discharge current.

Figure 3 Radial distributions of (a) the $\mathrm{O}$ densities in the presence and absence of DBD, and (b) the gas temperature. The $\mathrm{O}$ density in the presence of DBD was observed at $t=0.6$ $\mathrm{ms}$ in Fig. 2.

Figure 4 Radial distributions of (a) the ratio of the $\mathrm{O}$ densities in the presence and absence of $\mathrm{DBD}$, and (b) the gas temperature. The $\mathrm{O}$ density in the presence of DBD was observed at $t=0.6 \mathrm{~ms}$ in Fig. 2 .

Figure 5 Temporal variations of the ratio of the $\mathrm{O}$ densities in the presence and absence of DBD observed at radial positions of (a) $r=1.0 \mathrm{~mm}$, (b) $r=1.5 \mathrm{~mm}$, and (c) $r=2.0 \mathrm{~mm}$.

Figure 6 Radial distributions of the optical emission intensities of (a) $\mathrm{OH}$ and (b) Ar observed at $t=0.1$ and $0.6 \mathrm{~ms}$. The radial distribution of the optical emission intensity of $\mathrm{OH}$ in the absence of DBD is also shown in (a).

Figure 7 Relationship between the optical emission intensity of $\mathrm{Ar}$ and the increase in the optical emission intensity of $\mathrm{OH}$ by the superposition of DBD. The measurement times were (a) 0.1 and (b) $0.6 \mathrm{~ms}$.

Figure 8 Temporal evolutions of the densities of $\mathrm{H}, \mathrm{O}, \mathrm{OH}, \mathrm{CH}$, and $\mathrm{CHO}$, which were calculated using Chemkin. The gas mixture of $\mathrm{CH}_{4} / \mathrm{O}_{2} / \mathrm{Ar}$ is assumed. (a) simulates a conventional combustion without the superposition of DBD. An O density of $2 \times 10^{14} \mathrm{~cm}^{-3}$ is assumed in (b) as the initial value to simulate the combustion with the superposition of DBD. (c) and (d) show the same data as those in (a) and (b), respectively, in the linear time scale. 


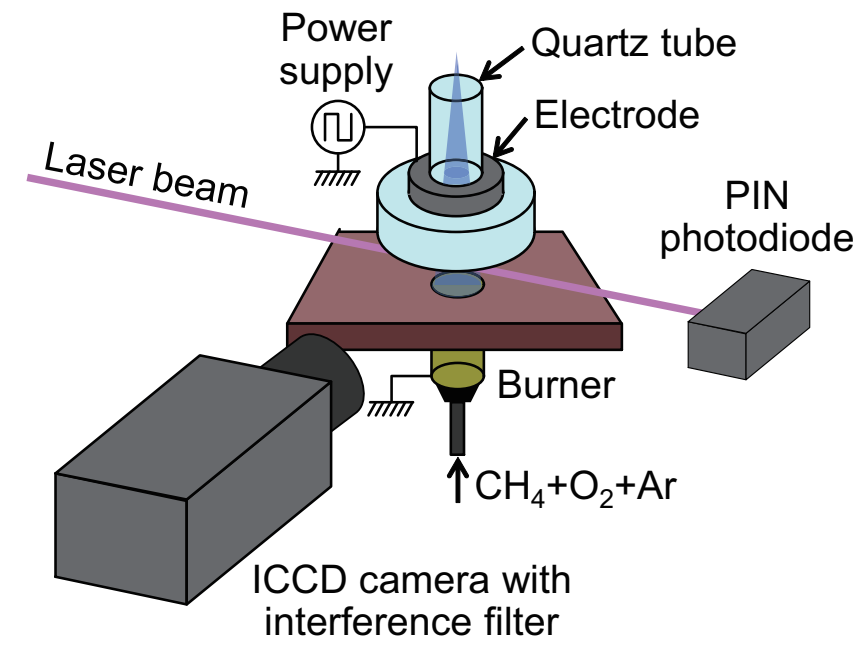

(a)

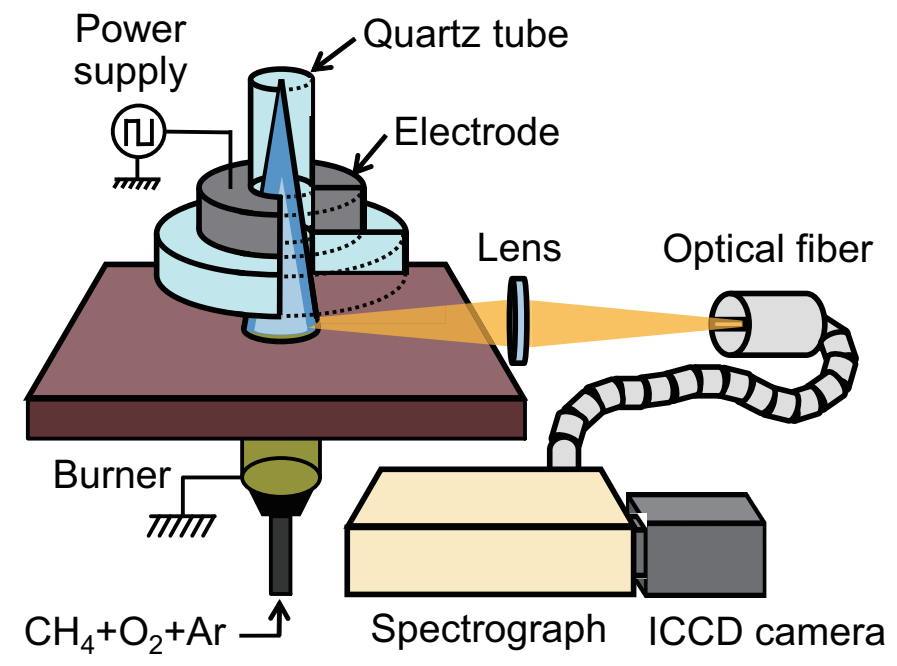

(b)

Fig. 1. Experimental apparatus. (a) Two-photon absorption laser-induced fluorescence for measuring the density of atomic oxygen and (b) spatially resolved optical emission spectroscopy for measuring the optical emission intensities of $\mathrm{OH}$ and Ar. 


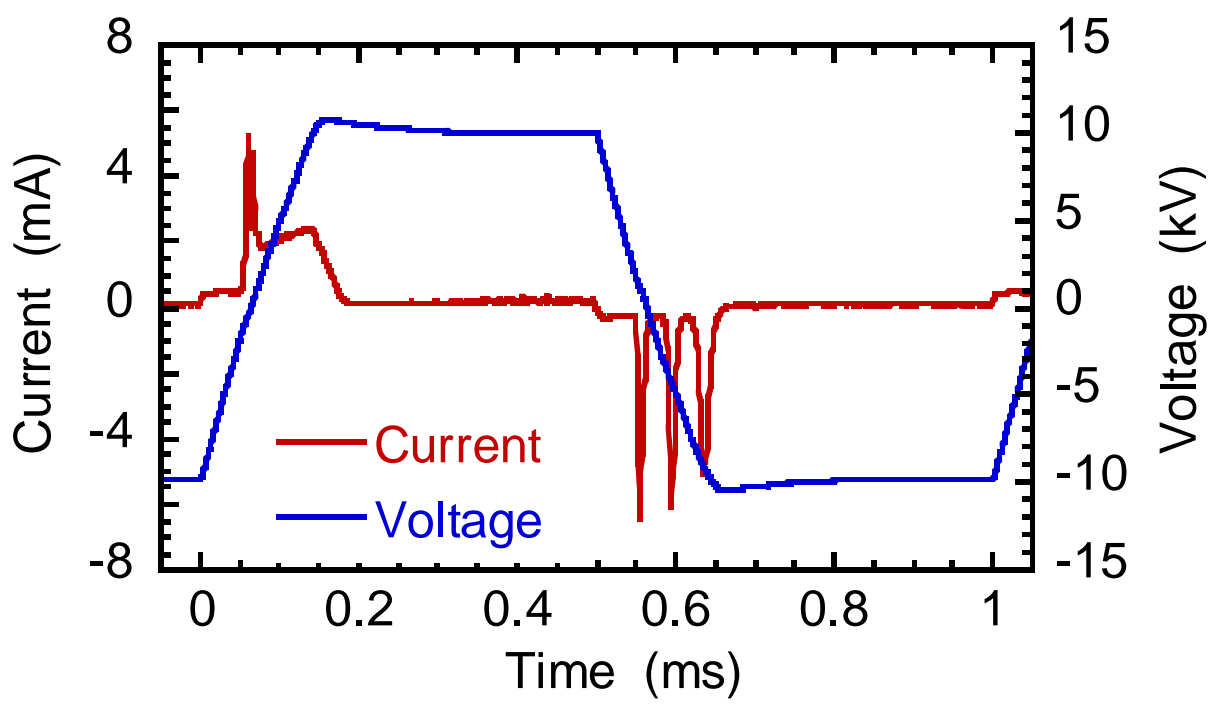

Fig. 2. Waveforms of the discharge voltage and the discharge current. 

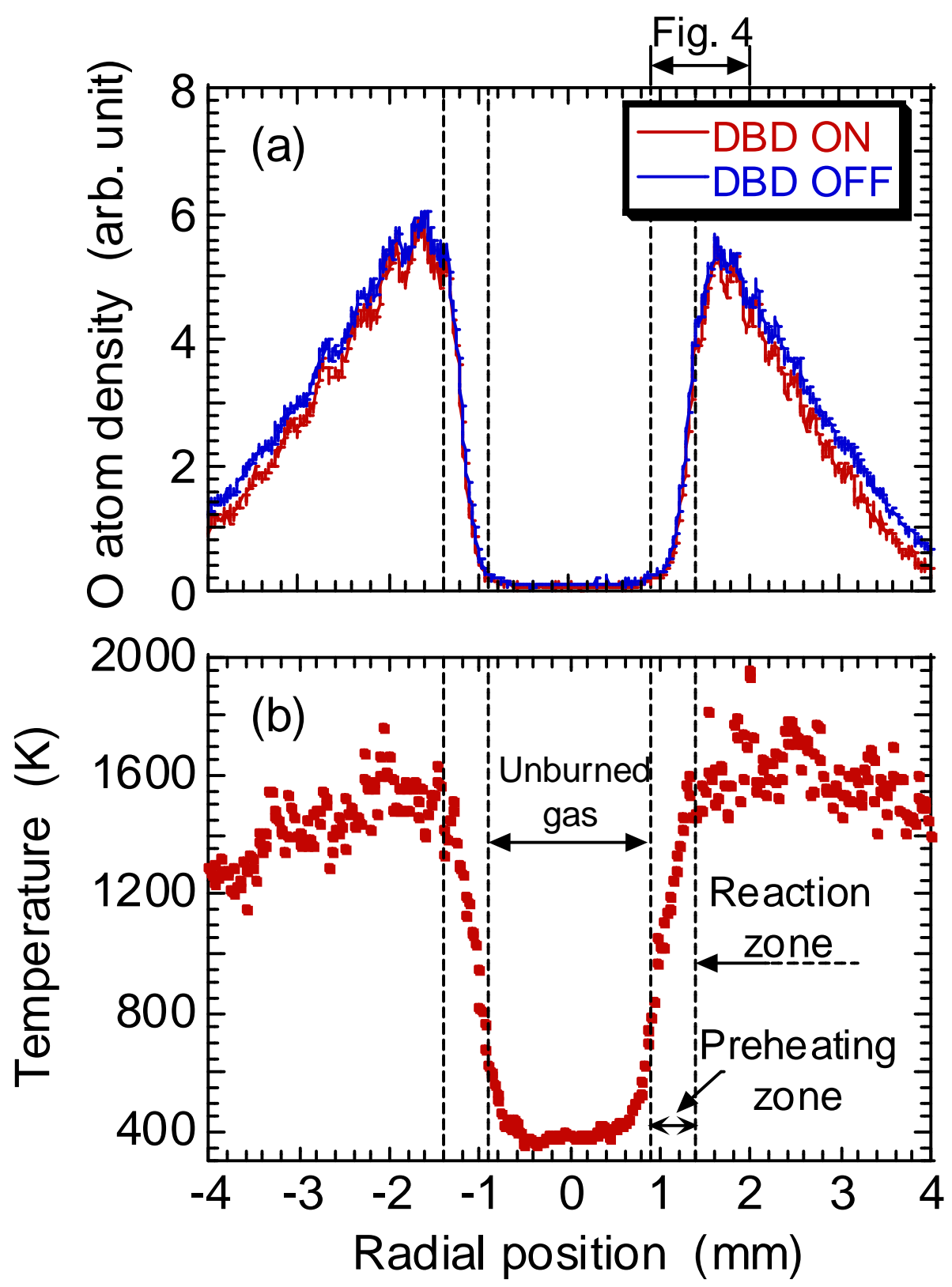

Fig. 3. Radial distributions of (a) the $\mathrm{O}$ densities in the presence and absence of $\mathrm{DBD}$, and (b) the gas temperature. The $\mathrm{O}$ density in the presence of DBD was observed at $t=0.6 \mathrm{~ms}$ in Fig. 2. 

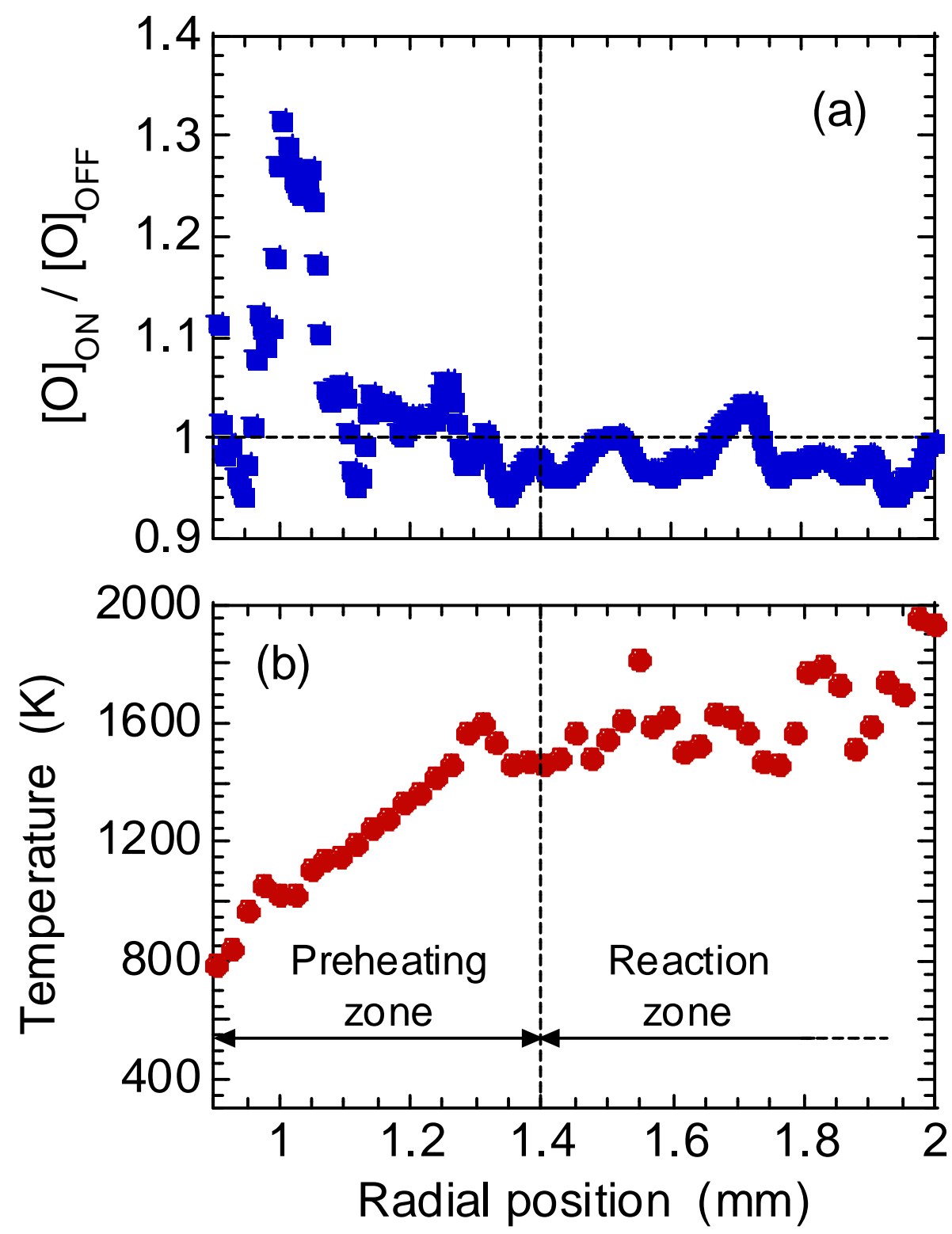

Fig. 4. Radial distributions of (a) the ratio of the $\mathrm{O}$ densities in the presence and absence of DBD, and (b) the gas temperature. The $\mathrm{O}$ density in the presence of DBD was observed at $t=0.6 \mathrm{~ms}$ in Fig. 2 . 

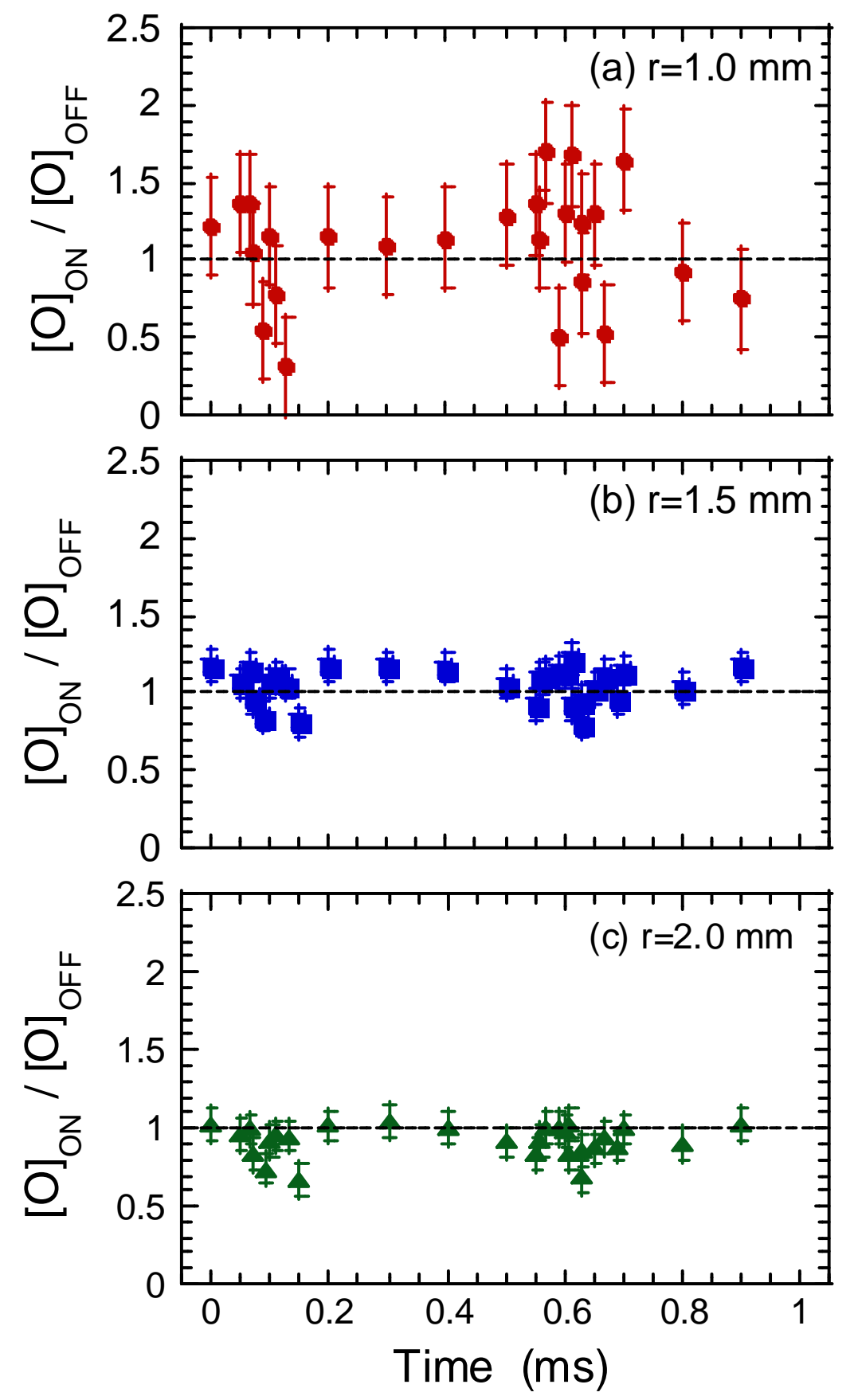

Fig. 5. Temporal variations of the ratio of the $\mathrm{O}$ densities in the presence and absence of DBD observed at radial positions of (a) $r=1.0 \mathrm{~mm}$, (b) $r=1.5 \mathrm{~mm}$, and (c) $r=2.0 \mathrm{~mm}$. 

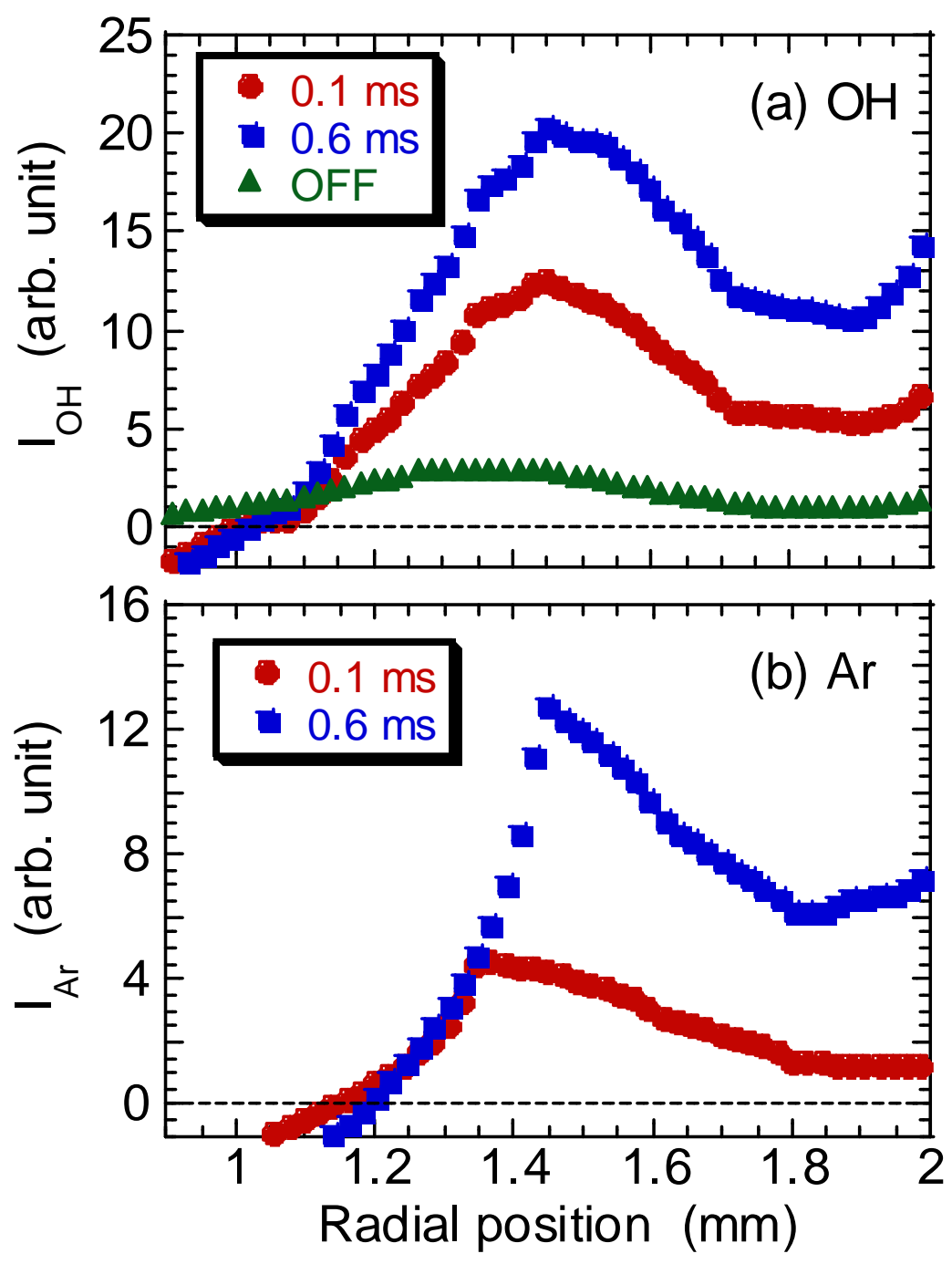

Fig. 6. Radial distributions of the optical emission intensities of (a) $\mathrm{OH}$ and (b) $\mathrm{Ar}$ observed at $t=0.1$ and $0.6 \mathrm{~ms}$. The radial distribution of the optical emission intensity of $\mathrm{OH}$ in the absence of DBD is also shown in (a). 


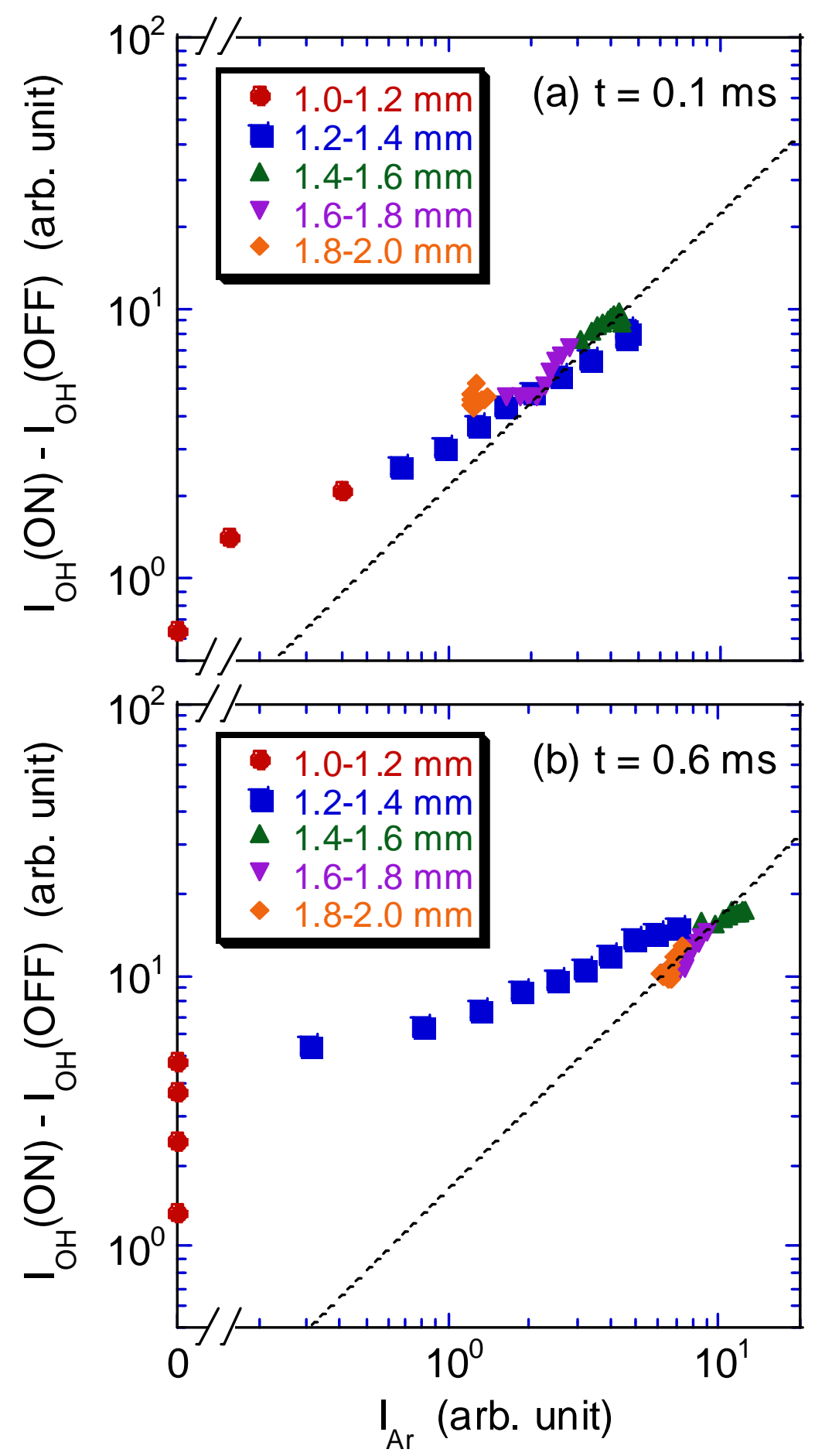

Fig. 7. Relationship between the optical emission intensity of Ar and the increase in the optical emission intensity of $\mathrm{OH}$ by the superposition of DBD. The measurement times were (a) 0.1 and (b) $0.6 \mathrm{~ms}$. 

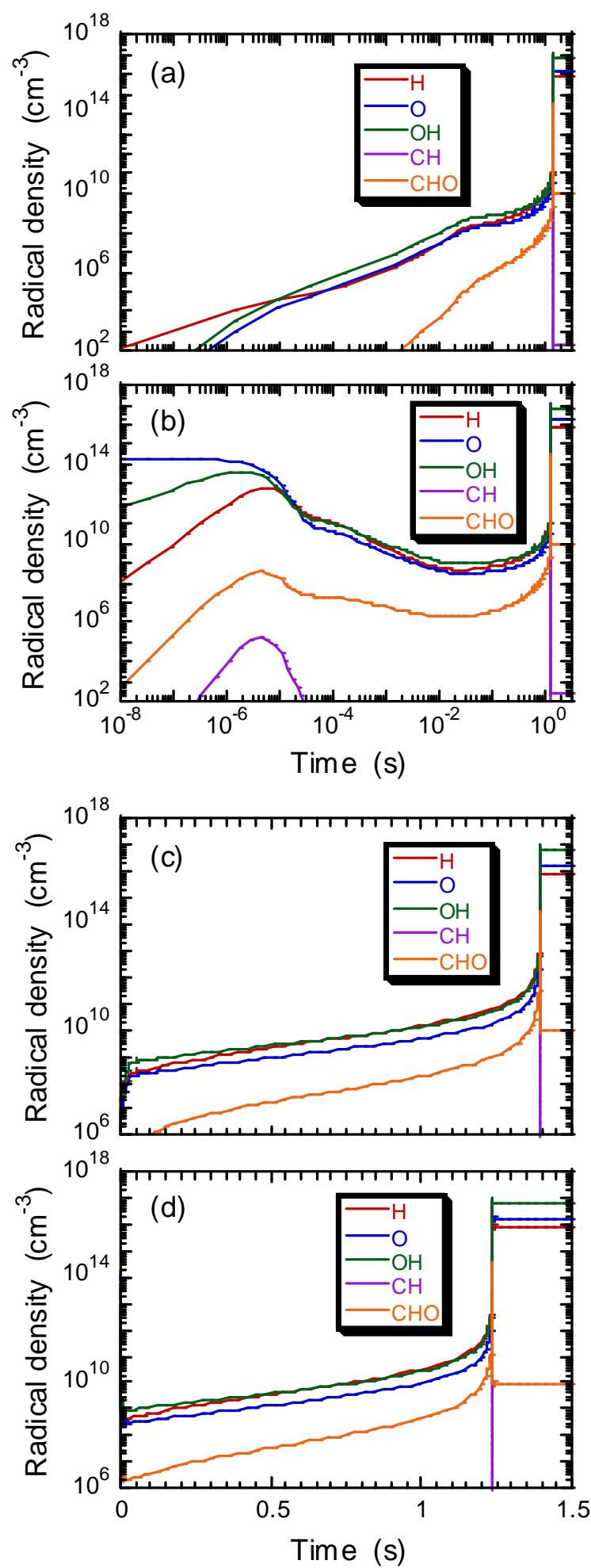

Fig. 8. Temporal evolutions of the densities of $\mathrm{H}, \mathrm{O}, \mathrm{OH}, \mathrm{CH}$, and $\mathrm{CHO}$, which were calculated using Chemkin. The gas mixture of $\mathrm{CH}_{4} / \mathrm{O}_{2} / \mathrm{Ar}$ is assumed. (a) simulates a conventional combustion without the superposition of DBD. An O density of $2 \times 10^{14} \mathrm{~cm}^{-3}$ is assumed in (b) as the initial value to simulate the combustion with the superposition of DBD. (c) and (d) show the same data as those in (a) and (b), respectively, in the linear time scale. 